hypertension due to hypoventilation or a patient with late diagnosed pulmonary arterial hypertension and consecutive respiratory failure. The treatment is different.

Another open question is how to treat patients with hypoventilation due to hypoventilation and residual pulmonary hypertension following noninvasive positive-pressure ventilation. Is this a vascular abnormality with a prognostic impact? Perhaps a look at cardiac index might be helpful.

For patients with pulmonary hypertension and lung disease, the current statement of the international conference on pulmonary hypertension recommends to separate patients with a predominantly exhausted circulatory or ventilatory reserve [4]. This is difficult in patients with severe pulmonary hypertension and hypoventilation. As we showed, these patients present with a high minute ventilation/carbon dioxide output slope but low respiratory exchange ratio and increasing end-tidal carbon dioxide tension reflecting a pattern which is different to that seen in patients with pulmonary arterial hypertension and patients with pure ventilatory impairment [1].

V. Cottin and co-workers encourage us to treat the underlying disease as stated in our study [1]. However, we believe that an additional prospective study is needed in order to obtain a clear idea of how to manage these specific patients with residual pulmonary hypertension despite effective noninvasive positive-pressure ventilation.

0

@ERSpublications

Effects of PH-specific drugs on persistent PH after effective NIPPV are unclear and should be studied prospectively http://ow.ly/xnN4k

Matthias Held

Dept of Internal Medicine, Medical Mission Hospital, Academic Teaching Hospital, Julius Maximillian University of Würzburg, Würzburg, Germany.

Correspondence: Matthias Held, Medical Mission Hospital, Academic Teaching Hospital, Julius Maximillian University of Würzburg, Salvatorstrasse 7, 97074 Würzburg, Germany. E-mail: matthias.held@missioklinik.de

Received: April 212014 | Accepted: May 252014

Conflict of interest: Disclosures can be found alongside the online version of this article at erj.ersjournals.com

\title{
References
}

Held M, Walthelm J, Baron S, et al. Functional impact of pulmonary hypertension due to hypoventilation and changes under noninvasive ventilation. Eur Respir J 2014; 43: 156-165.

Held M, Jany B. Pulmonary hypertension in COPD. Respir Care 2013; 58: e 86-e91.

Meyer FJ, Lossnitzer D, Kristen AV, et al. Respiratory muscle dysfunction in idiopathic pulmonary arterial hypertension. Eur Respir J 2005; 25: 125-130.

4 Seeger W, Adir Y, Barbera JA, et al. Pulmonary hypertension in chronic lung disease. J Am Coll Cardiol 2013; 62: D110-D115.

Eur Respir J 2014; 44: 821-822 | DOI: 10.1183/09031936.00073914 | Copyright @ERS 2014

\section{The cost of tuberculosis sequelae}

To the Editor:

We read with great interest the article by DiEL et al. [1], which analysed the total average cost of tuberculosis (TB) per case for the current 27 member states of the European Union (EU-27). The average combined direct and indirect cost of TB in the original EU-15 (Austria, Belgium, Denmark, Finland, France, Germany, Greece, Ireland, Italy, Luxembourg, the Netherlands, Portugal, Spain, Sweden and the UK), plus Cyprus, Malta and Slovenia (EU-18), was calculated to be $€ 10282$ for drug-susceptible TB, $€ 57213$ for multidrugresistant $\mathrm{TB}$ (MDR-TB) and $€ 170744$ for extensively drug-resistant TB (XDR-TB). According to differences in the gross domestic product, the total average cost in the remaining nine countries was extrapolated to be one-third of the mean cost in the EU-18: €3427 for drug-susceptible TB and $€ 24166$ for MDR-TB/XDR-TB. When taking into account the 103104 disability-adjusted life years caused by TB, the total cost of treating TB patients in the EU-27 in 2012 was estimated to be $>€ 5$ billion [1].

As acknowledged by Diel et al. [1], there are various limitations associated with their estimation of the total cost of TB in the EU-27. One of the limitations is that although the disability weight of TB $(0.271)$ might 
take the additional burden of TB sequelae into consideration, these conditions also possess individual direct and indirect costs [1]. Primary and post-primary TB patients are vulnerable to a number of pulmonary and extra-pulmonary sequelae, as described by KIM et al. [2]. Here we will just mention a few, but we suggest that future TB cost analysis focuses on all of them.

Systematic analysis of the costs of TB cases is particularly relevant in developing countries where limited resources mean it is important to make informed decisions when allocating funds. The additional cost of treating sequelae should be taken into account when considering the total economic burden of TB. In a study carried out by CABRERA-RIVERO [3], 41.6\% of patients discharged from the Tuberculosis Control Programme (TCP) at the Hospital Nacional Cayetano Heredia (Lima, Peru) possessed sequela symptoms.

Bronchiectasis is one of the most common sequelae seen in TB patients; the morbidity is reported to be as high as $30-60 \%$ in active post-primary patients and $71-86 \%$ in patients with inactive disease $[2,4]$. Furthermore, depending on the survival status of patients, the inpatient cost of treating bronchiectasis in the USA can be as high as $€ 393872$ [5].

Other important sequelae include aspergillus and haemoptysis. Cornejo GARCía [6] found that $8.82 \%$ of patients discharged from the Hospital Nacional Cayetano Heredia (Lima, Peru) TCP had positive serology for aspergillus. In 2009, the cost of treating aspergillus in the USA was estimated to be €68 787, which meant it was $€ 34838-58270$ higher than in those patients without this infection [7]. Regarding haemoptysis, $13.76 \%$ of TCP outpatients were diagnosed during home visits post discharge, incurring additional cost [8].

When considering the rationale of developing a new TB vaccine, it is important to consider that it will benefit patients around the globe. The most recent World Health Organization report estimated there were 8.6 million incident cases of TB in 2012, equating to an average of 122 cases per 100000 population [9]. In that year, only $4 \%$ of these cases occurred in Europe, "a small percentage of the disease globally" [10]. It is clear that DIEL et al. [1] were correct when they stated that investment in a new TB vaccine is cost-effective, as there is no doubt that the economic burden of treating TB patients in all seven continents far exceeds the Tuberculosis Vaccine Initiative's investment model of $€ 560$ million. However, until a TB vaccine is developed, understanding the burden of individual sequela will enable more informed decisions to be made when considering tertiary prevention in TB patients.

0 @ERSpublications

The real cost of tuberculosis sequelae demonstrates the cost-effectiveness of developing a TB vaccine http://ow.ly/wCxka

Alvaro Proaño ${ }^{1}$, William Rudgard ${ }^{2}$ and Oscar Gayoso ${ }^{3}$

${ }^{1}$ Facultad de Medicina Alberto Hurtado, Universidad Peruana Cayetano Heredia, Lima, Peru. ${ }^{2}$ College of Medical and Dental Sciences, University of Birmingham, Birmingham, UK. ${ }^{3}$ Pulmonology Dept, Hospital Nacional Cayetano Heredia, Lima, Peru.

Correspondence: Alvaro Proaño, Facultad de Medicina Alberto Hurtado, Universidad Peruana Cayetano Heredia, Av. Honorio Delgado 430 Urb. Ingeniería, San Martin de Porres, Lima, Peru. E-mail: alvaro.proano.f@upch.pe

Received: April 022014 | Accepted: April 072014

Conflict of interest: Disclosures can be found alongside the online version of this article at erj.ersjournals.com

\section{References}

1 Diel R, Vandeputte J, de Vries G, et al. Costs of tuberculosis disease in the European Union: a systematic analysis and cost calculation. Eur Respir J 2014; 43: 554-565.

2 Kim HY, Song KS, Goo JM, et al. Thoracic sequelae and complications of tuberculosis. Radiogr Rev Publ Radiol Soc N Am Inc 2001; 21: 839-858.

3 Cabrera-Rivero JL. Prevalencia de alteraciones funcionales pulmonares de la tuberculosis secuelar en pacientes dados de alta del programa de control de tuberculosis del Hospital Cayetano Heredia entre los años 1984-1996. [Prevalence of pulmonary functional alterations due to secuelar tuberculosis in discharged patients from the Tuberculosis Control Programme in Hospital Nacional Cayetano Heredia during the years 1984 and 1996.] Bachelor of medicine thesis. Universidad Peruana Cayetano Heredia, Lima, Peru, 1999.

4 Pedrozo Pupo JC. Air space and bronchi - II. In: Pedrozo Pupo JC, Rada Escobar R, Gonzalez Mejia E, et al. Learning Chest Imaging. Berlin, Springer, 2013; pp. 107-133.

5 Seitz AE, Olivier KN, Steiner CA, et al. Trends and burden of bronchiectasis-associated hospitalizations in the United States, 1993-2006. Chest 2010; 138: 944-949.

6 Cornejo García JG. Prevalencia de serología para aspergillus en pacientes dados de alta del programa de control de tuberculosis y en pacientes de consulta externa de neumología en el Hospital Nacional Cayetano Heredia entre 1984-1996. [Prevalence of aspergillus serology in discharged patients from the Tuberculosis Control Programme and outpatients from Hospital Nacional Cayetano Heredia during the years 1984 and 1996.] Bachelor of medicine thesis. Universidad Peruana Cayetano Heredia, Lima, Peru, 1999. 
Krueger KP, Nelson AC. Economic considerations in the treatment of invasive aspergillosis: a review of voriconazole pharmacoeconomic studies. Clin Outcomes Res 2009; 1: 35-43.

8 Aguilar Aragón JA, Cabrera Rivero JL, Cornejo Garcia J, et al. Prevalencia de hemoptisis luego de la cura bacteriológica en pacientes dados de alta del Programa de Control de Tuberculosis del Hospital Nacional Cayetano Heredia. [Haemoptysis prevalence after bacteriological cure in discharged patients from the Tuberculosis Control Programme from Hospital Nacional Cayetano Heredia.]. Rev Medica Hered 2003; 14: 167-174.

9 World Health Organization. Global tuberculosis report 2013. Geneva, World Health Organization, 2013.

10 Walls T, Shingadia D. The epidemiology of tuberculosis in Europe. Arch Dis Child 2007; 92: 726-729.

Eur Respir J 2014; 44: 822-824 | DOI: 10.1183/09031936.00062314 | Copyright @eERS 2014

From the author:

We thank A. Proaño and co-workers for their important comments on our cost analysis of tuberculosis (TB) in the European Union [1]. As pointed out in our study, the cost calculation only refers to direct treatment costs of the disease itself under the implicit assumption that treatment success has either been gained over 24 months or, alternatively, that according to the official World Health Organization data a minor percentage of patients (shown separately for fully susceptible TB and multidrug-resistant (MDR)TB) will die immediately afterwards. In addition, to our knowledge, the disability weight of 0.271 used to calculate disability-adjusted life years includes only the clinical stage of TB disease without considering any sequelae after treatment.

We fully agree with A. Proaño and co-workers that sequelae of TB should be included in cost calculations as far as possible to further enhance the economic weight of that disease. In terms of costs, however, we have to differentiate between radiographic abnormalities, as described by KIM et al. [2], and clinical consequences sui generis that need to be treated in the long run. Thus, for bronchiectasis, from an economic point of view the question that has to be answered is how many patients with radiological signs of bronchiectasis simultaneously suffer from chronic lung disorders, characterised by cough, sputum production and recurrent respiratory infections and/or frequently associated chronic obstructive lung disease? The latter group of patients seems to differ from other patients with bronchiectasis in terms of disease severity, more frequent detection of Pseudomonas aeruginosa and other potential pathogenic microorganisms, more frequent exacerbations and increased mortality [3-5]. However, the major burden of clinically manifest bronchiectasis may be managed in the outpatient setting by primary care physicians and pulmonologists in private practice and, thus, neither the prevalence of bronchiectasis in general nor TB-induced bronchiectasis is accurately known.

In our patients, most of whom are immunocompetent, pulmonary aspergillosis as a complication of TB is rare and only occasionally found in cavities of the destroyed lungs of mismanaged MDR-TB patients. In addition, haemoptysis, which occurred in $\sim 14 \%$ of patients following TB, as stated by A. Proaño and coworkers, may be seen as an eventual indicator of untreated manifest disease rather than as a post-treatment complication.

Nevertheless, there are also additional consequences predisposed by prior TB disease, such as infections with non-tuberculous mycobacteria [6] or lung cancer, of which the latter is seen in an $\sim 11$-fold higher incidence in TB patients [7] versus the general population bringing with it significant costs. We would like to take advantage of this opportunity to state that we intend, in the near future, to conduct a systematic follow-up of German TB patients to catalogue the modern clinical consequences of this ancient disease and the respective costs. We respectfully agree with our distinguished colleagues that such studies are needed.

@ERSpublications

Significant post-treatment costs may arise due to tuberculosis sequelae, but these still have to be determined http://ow.ly/xbwHW

Roland Diel

Institute for Epidemiology, University Hospital Schleswig-Holstein, Airway Research Center North, Member of the German Center for Lung Research (DZL), Kiel, Germany.

Correspondence: Roland Diel, Institute for Epidemiology, University Hospital Schleswig-Holstein, Niemannsweg 11, 24105 Kiel, Germany. E-mail: roland.diel@epi.uni-kiel.de

Received: May 192014 | Accepted: May 202014

Conflict of interest: None declared. 